\title{
Subject Index Vol. 6, No. 4-6, 1997
}

Acetylcholine 201 Adrenal medulla 255 Aging 301 Anisomycin 212 Area postrema 255

Brain water 255

Malondialdehyde 291 Melatonin 191,217,22*5,233, 241,247^264,284,291, 301 Microdialysis 233

Norepinephrine 201 Nucleus tractus solitarii 255

Calcium influx 284

- mobilization 284

- oscillations 201 Cationic channel 212 Cell membranes 291 Circadian oscillator(s) 191,212

- rhythm(s) 217,225,233,241,247,264,301,307

Cyclic AMP 191,217,272

Daily rhythm 225 Development 272 Diurnal rhythm 272 Dopamine 191,233

Entrainment 307 Epinephrine neuron 255 Excitatory amino acids 247

Opioid 255 Oxidative damage 291

Parapineal organ 185 Photoperiod 264 Photoreceptor 191,217 Pigeon 233 Pineal 212,233

- gland 255,264,272,301

- organ 185,225,241 Pinealectomy 272 Pinealocytes 201 Preganglionic sympathetic neuron

255 Protein synthesis 212

Quantitative morphology 255 Quipazine 247

Eisn 225

Gonadotrophs 284

Rainbow trout 201

Rat 201

Retina 191,217,225,233

Internal desynchronization 307 Intracellular free calcium 284 Intracranial surgery 255 Iron overload 291

Japanese quail 233

I^type calcium channels 201 Lamprey 185,241 Light 217

S-antigen 201 Serotonin 247

- immunoreactive photoreceptor 185 »

- $\quad \mathrm{r}^{\wedge}$ Setyltransferase $217 \cdot$ Sleep-wake 307Suprachiasmatic nucleus 247

Three-dimensional structure 185 